Proc. of the X Int. Conf. — Ion Implantation and other Applications of Ions and Electrons, Kazimierz Dolny 2014

\title{
The Corrosion Enhancement due to Plasma Post-Oxidation Subsequent to Plasma Nitriding of a Steel AISI 4140
}

\author{
A.E. Muñoz-Castro ${ }^{a, *}$, A. De la Piedad-Beneitez ${ }^{b}$, R. VAlencia-Alvarado $^{a}$, \\ R. López-Callejas ${ }^{a, b}$, A. Mercado-Cabrera ${ }^{a}$, R. Peña-Eguiluz ${ }^{a}$ \\ AND B.G. RODRIGUEZ-MENDEZ ${ }^{a}$ \\ ${ }^{a}$ Instituto Nacional de Investigaciones Nucleares, Plasma Physics Laboratory, \\ AP 18-1027, CP 11801, Mexico D.F., Mexico \\ ${ }^{b}$ Instituto Tecnológico de Toluca, Av. Tecnológico S/N, AP 890, Toluca, Mexico
}

\begin{abstract}
The corrosion enhancement due to plasma post-oxidation subsequent to plasma nitriding of the samples of low alloy annealed steel AISI 4140 was evaluated. The plasma nitriding was carried out at $\approx 570{ }^{\circ} \mathrm{C}$ for $1-3 \mathrm{~h}$ in an atmosphere of $75 \% \mathrm{H}_{2}$ and $25 \% \mathrm{~N}_{2}$. After this process post-oxidation at $\approx 450{ }^{\circ} \mathrm{C}$ in a gas mixture, air and dry air-like was conducted for an hour. The treated samples were characterized using the XRD, SEM, AFM, potentiodynamic polarization and Vickers microhardness tests. The outcome of combined processes showed the presence of $\varepsilon$ and $\gamma^{\prime}$ nitrided phases in the inner compound layer and in the outer one mostly of magnetite phase and barely visible of hematite one without using $\mathrm{H}_{2}$ in the post-oxidation process. Also in these processes, the corrosion potential proved to be lower in the treated specimens than the untreated ones, and the corrosion current decreased up to one order of magnitude when treated in environment air and air-like ambient.
\end{abstract}

DOI: 10.12693/APhysPolA.128.824

PACS: 52.77.-j, 52.40.Hf, 81.40.-z, 81.65.-b, 81.65.Mq

\section{Introduction}

It is unanimously recognized in the literature that the aim of post-oxidation is to have a $\mathrm{Fe}_{3} \mathrm{O}_{4}$ (magnetite) layer avoiding $\alpha-\mathrm{Fe}_{2} \mathrm{O}_{3}$ (hematite) on the ferrous alloy surfaces subsequent to plasma nitriding in order to enhance the tribological properties and corrosion resistance [1] whereas the iron nitriding increases the wear resistance. The latter can be achieved through the formation of an inner compound layer consisting of $\varepsilon-\mathrm{Fe}_{2-3} \mathrm{~N}, \gamma^{\prime}-\mathrm{Fe}_{4} \mathrm{~N}$ and other nitrides [2]; the former through an outer layer which should essentially contain magnetite, a very low content of hematite and probably $\mathrm{FeO}$ as well. The hematite phase layer is porous, brittle and a little adherent [3] while the magnetite one denser and more homogeneous so with a higher corrosion performance and a lower friction coefficient [4].

Nowadays the interest in post-oxidation in low alloy steels has grown including plain steels $[5,6]$. The applications of this duplex process are to improve the surface properties of pump components, spring washers under corrosive and tribological loads [7] and to provide a highperformance mechanical system for hydraulic and automotive parts [3, 8]. Attempts were made to conduct on post-oxidation processes with different atmospheres: $\mathrm{O}_{2}$, $\mathrm{H}_{2} \mathrm{O}$ and $\mathrm{CO}_{2}$ with or without $\mathrm{H}_{2}$ or $\mathrm{Ar}$ in order to obtain magnetite resulting in the presence of hematite $[6,8,9]$. This paper is focused on investigating the anticorrosive

*corresponding author; e-mail: arturo.munoz@inin.gob.mx effect of plasma post-oxidation in the two types of atmospheres: dry air-like (dal) and environmental air (air) without using $\mathrm{H}_{2}$ after plasma nitriding on low alloy AISI 4140 steel.

\section{Experimental}

Annealed low alloy AISI 4140 steel of the following chemical composition (in wt\%): $0.40 \mathrm{C}, 0.90 \mathrm{Mn}, 0.03 \mathrm{P}$, $0.03 \mathrm{~S}, 0.25 \mathrm{Si}, 0.95 \mathrm{Cr}, 0.20 \mathrm{Mo}$ and Fe balance. The samples used in this study were discs of $9 \mathrm{~mm}$ diameter and $3 \mathrm{~mm}$ thick cut off a rod of $12.7 \mathrm{~mm}$ diameter. The samples were machined, polished using $\mathrm{SiC}$ grits from 600 to 2000 and ultrasonically cleaned in acetone before being placed into the reactor.

The ion nitriding on the samples was achieved by a RF inductive discharge in $75 \% \mathrm{H}_{2}$ and $25 \% \mathrm{~N}_{2}$ atmosphere at $6 \mathrm{~Pa}$ working pressure after been evacuated down to a $5 \times 10^{-2} \mathrm{~Pa}$ base pressure. Before their treatment, the samples were finally cleansed by a twentyminute bombardment with Ar ions. The samples were nitrided for one $(1 \mathrm{hN})$, two $(2 \mathrm{hN})$ and three $(3 \mathrm{hN})$ hours at $\approx 570^{\circ} \mathrm{C}$ [10]. Post-oxidation was performed for one hour ( $1 \mathrm{hPO}$ ) at $\approx 450^{\circ} \mathrm{C}$, in the two types of atmosphere: in extra dry air-like (dal) and in environmental air (air).

The compound and oxidized layers were observed and the depths measured by scanning electron microscopy (SEM). For this purpose the samples were previously cross-sectionally cut, metallographically prepared and etched with a $2.5 \%$ Nital solution. In order to follow up the microstructure evolution, a scanning electron microscope was used while the energy dispersive spectroscopy (EDS) technique was applied in order to evaluate the nitrogen and oxygen contents. X-ray diffraction of $\mathrm{Cu} K_{\alpha}$ 
radiation $(1.5405 \AA)$ determined the phases. The filler effect of post-oxidation was evidenced by the atomic force microscopy (AFM) micrographs. The surface microhardness was assessed with a Vickers tester using a $500 \mathrm{~g}$ load by averaging every six measurements. Potentiodynamic tests in $3.5 \% \mathrm{NaCl}$ solution were applied at room temperature with the potentials ranging from -800 to $1200 \mathrm{mV}$ (with respect to a saturated calomel electrode) at a scan rate of $1 \mathrm{mV} / \mathrm{s}$ so as to determine the corrosion performance.

\section{Results and discussion}

In order to investigate the surface morphology and elemental content, the SEM and EDS analyses were made. The SEM micrograph in Fig. 1 shows the oxidized surface topography of a typical sample before being nitrided. There are three types of zones: white and black, white, and black; the EDS analyses show iron oxides and carbon formation. The zone mostly representative is that

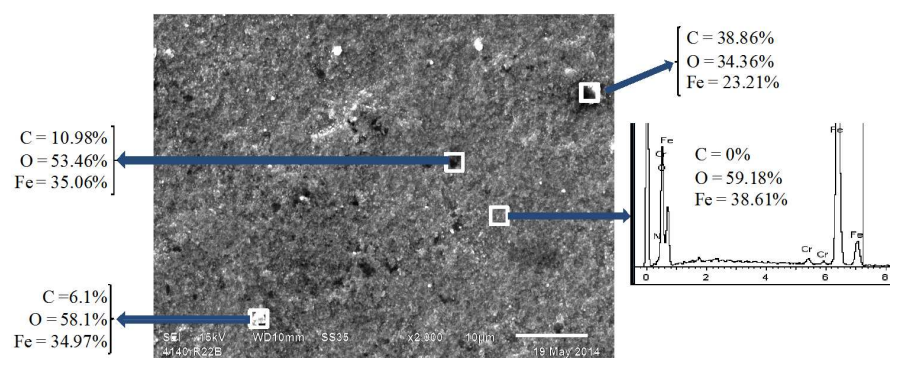

Fig. 1. Topographic view of the oxidized layer of a typical sample. of the arrow pointing to the EDS spectrum with no carbon content, therefore, there is no significant presence of re-deposition. The EDS analyses in at.\% of oxygen, iron and nitrogen, as well as the corresponding $\mathrm{O} / \mathrm{Fe}$ and $\mathrm{O} / \mathrm{N}$ ratio in the surface layer are listed in Table I, $1 \mathrm{hN}+1 \mathrm{hPO}$ means a one hour nitriding and an hour postoxidation. The $\mathrm{O} / \mathrm{Fe}$ ratio indicates estimation of oxygen content which could be attributed to the formation of small amounts of $\mathrm{Fe}(\mathrm{OH})_{2}, \mathrm{Fe}(\mathrm{OH})_{3}$, etc. The sample treated at $2 \mathrm{hN}+1 \mathrm{hPO}$ with environmental air at both $\mathrm{O} / \mathrm{Fe}$ and $\mathrm{O} / \mathrm{N}$ ratios is the lowest compared to other samples treated which indicates formation of magnetite phase.

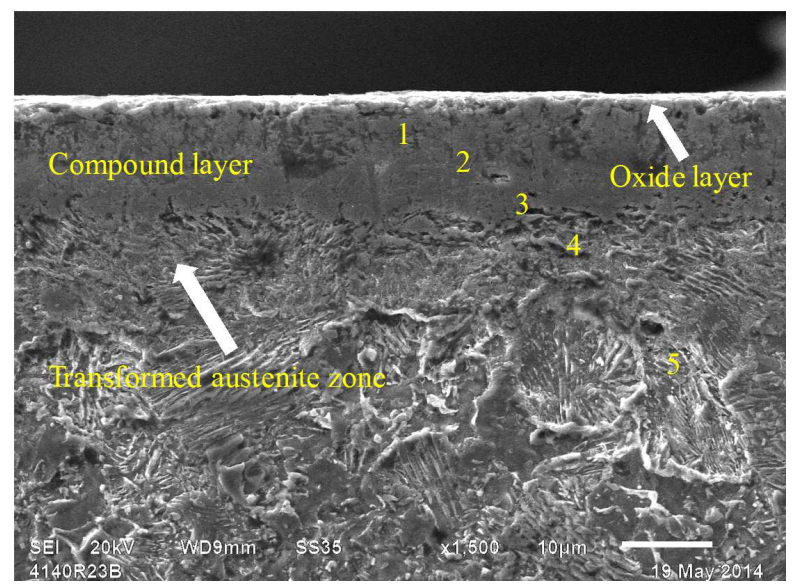

Fig. 2. Cross-view of the compound and oxidized layers of a typical sample.

Atomic percentage of the oxidized layer by EDS.

TABLE I

\begin{tabular}{|c|c|c|c|c|c|c|c|c|c|c|c|c|}
\hline \multirow{5}{*}{ Ratios } & \multicolumn{6}{|c|}{ Dry air } & \multicolumn{6}{|c|}{ Environmental air } \\
\hline & \multicolumn{2}{|c|}{$1 \mathrm{hN}+1 \mathrm{hPO}$} & \multicolumn{2}{|c|}{$2 \mathrm{hN}+1 \mathrm{hPO}$} & \multicolumn{2}{|c|}{$3 \mathrm{hN}+1 \mathrm{hPO}$} & \multicolumn{2}{|c|}{$1 \mathrm{hN}+1 \mathrm{hPO}$} & \multicolumn{2}{|c|}{$2 \mathrm{hN}+1 \mathrm{hPO}$} & \multicolumn{2}{|c|}{$3 \mathrm{hN}+1 \mathrm{hPO}$} \\
\hline & \multicolumn{2}{|c|}{$\% \mathrm{O}=60.35$} & \multicolumn{2}{|c|}{$\% \mathrm{O}=59.38$} & \multicolumn{2}{|c|}{$\% \mathrm{O}=60.4$} & \multicolumn{2}{|c|}{$\% \mathrm{O}=55.69$} & \multicolumn{2}{|c|}{$\% \mathrm{O}=54.36$} & \multicolumn{2}{|c|}{$\% \mathrm{O}=59.18$} \\
\hline & $\% \mathrm{Fe}$ & $\% \mathrm{~N}$ & $\% \mathrm{Fe}$ & $\% \mathrm{~N}$ & $\% \mathrm{Fe}$ & $\% \mathrm{~N}$ & $\% \mathrm{Fe}$ & $\% \mathrm{~N}$ & $\% \mathrm{Fe}$ & $\% \mathrm{~N}$ & $\% \mathrm{Fe}$ & $\% \mathrm{~N}$ \\
\hline & 32.29 & 0.96 & 31.47 & 3.91 & 37.54 & 1.02 & 37.05 & 4.28 & 37.25 & 5.16 & 38.61 & 3.76 \\
\hline $\begin{array}{l}\mathrm{O} / \mathrm{Fe} \\
\mathrm{O} / \mathrm{N}\end{array}$ & \multicolumn{2}{|c|}{1.87} & \multicolumn{2}{|c|}{1.88} & \multicolumn{2}{|c|}{59.21} & \multicolumn{2}{|c|}{1.50} & \multicolumn{2}{|c|}{10.53} & 15.73 & \\
\hline
\end{tabular}

The SEM micrograph in Fig. 2 depicts the compound nitrided layer, oxidized layer, and transformed austenite zone, observed in differently treated samples. This reflects the compound and oxidized layers stability due to this type of treatment. The EDS technique associated with SEM was used in order to evaluate the nitrogen content from the EDS spectra in the zones: (1) 23.4 at.\%, (2) 27.8 at.\%, (3) 18.3 at.\%, (4) 15.29 at.\% and (5) 0 at.\%. It means that in the central part of compound layer there is a maximum, decreasing toward the inner and outer zones as previously evaluated for the other samples which were only nitrided [10].

Figure 3 displays the AFM image of the sample before and after of oxidation treatment. It can be seen that the filler effect on the oxidized specimen (Fig. 3c, e, g) is evident in comparison with the nitrided samples (Figs. 3b, $\mathrm{d}, \mathrm{f})$. Comparing the untreated samples with nitrided and nitrided and post-oxidized ones, improvement in the smoothing of the latter can be observed. On the other hand, in the only nitrided samples, there is no difference in their morphology evidencing a low etching effect due to very low bias voltage on the samples.

XRD patterns of the untreated (Fig. 4a), nitrided (Fig. 4b) and nitrided post-oxidized (Fig. 4c-h) samples are shown in Fig. 4. The surface layer of the nitrided sample consists mainly of $\gamma^{\prime}-\mathrm{Fe} 4 \mathrm{~N}$ and $\varepsilon-\mathrm{Fe}_{2-3} \mathrm{~N}$ phases with a small diffraction peak of $\alpha$-Fe phase. After 

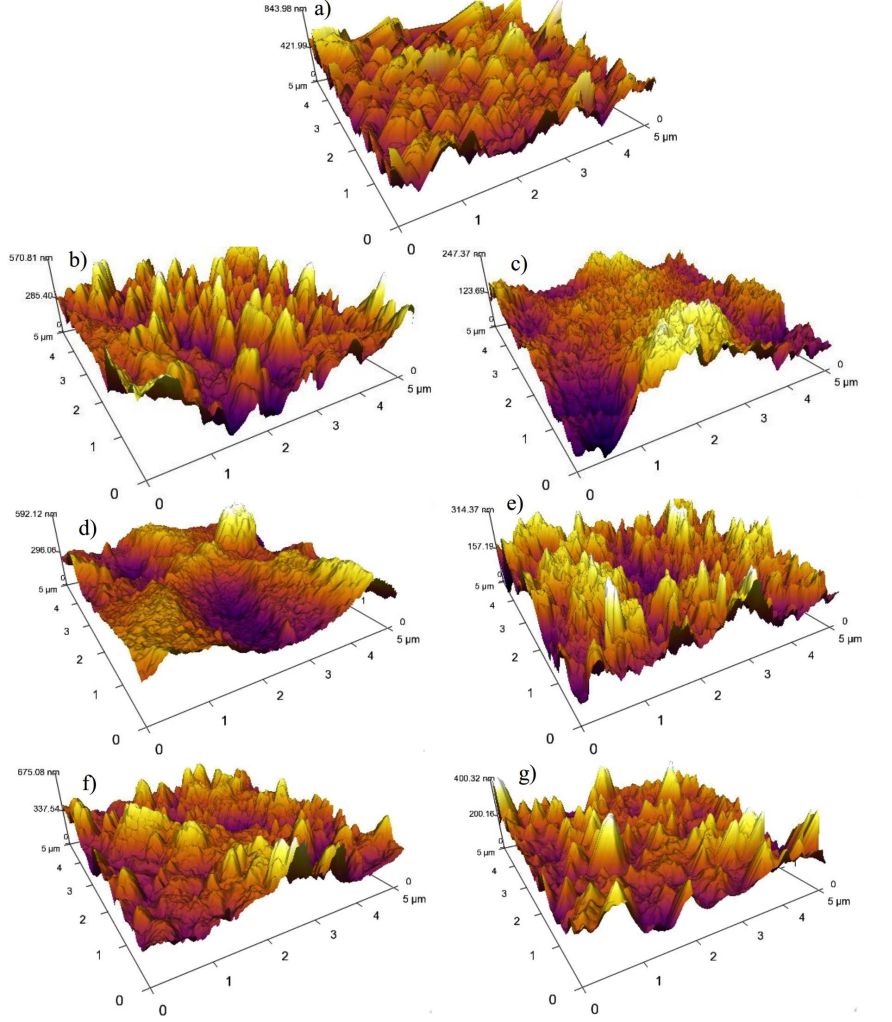

Fig. 3. Morphology of surface by AFM.

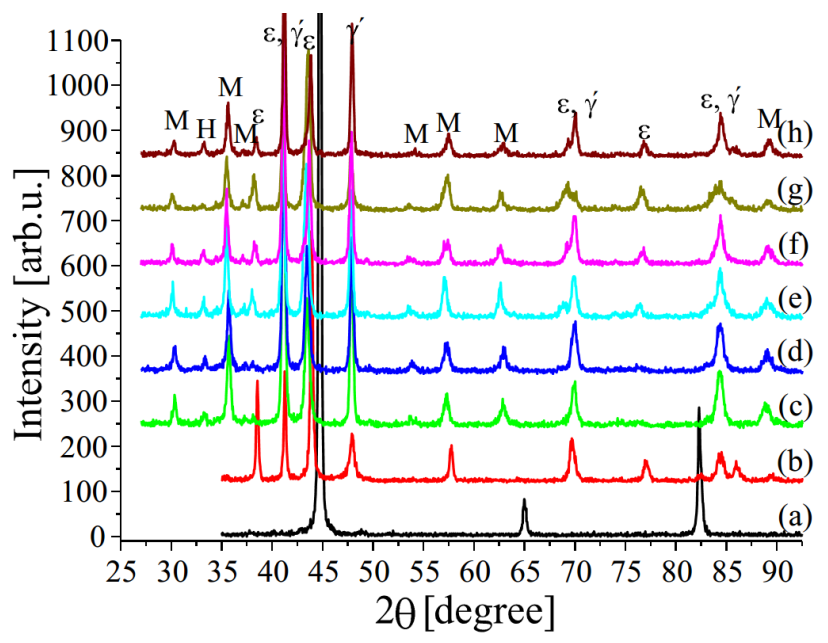

Fig. 4. Diffractogram corresponding to: (a) AISI 4140 untreated, (b) nitrided sample, (c) $1 \mathrm{hN}+1 \mathrm{hPO}_{\text {dal }}$, (d) $2 \mathrm{hN}+1 \mathrm{hPO}_{\text {dal }}$, (e) $3 \mathrm{hN}+1 \mathrm{hPO}$ dal, (f) $1 \mathrm{hN}+1 \mathrm{hPO}$ air (g) $2 \mathrm{hN}+1 \mathrm{hPO} \mathrm{air},(\mathrm{h}) 3 \mathrm{hN}+1 \mathrm{hPO}$ air. These graphs show the following phases: $\varepsilon-\mathrm{Fe}_{2-3} \mathrm{~N}, \gamma^{\prime}-\mathrm{Fe}_{4} \mathrm{~N}$, magnetite $\left(\mathrm{M}=\mathrm{Fe}_{3} \mathrm{O}_{4}\right)$ and hematite $\left(\mathrm{H}=\mathrm{Fe}_{2} \mathrm{O}_{3}\right)$.

the post-oxidation process, formation of magnetite phase in all treated samples is evident. Particularly, for the post-oxidized samples with dry-air the hematite phase at $2 \theta \approx 33.1^{\circ}$ is also present; this is shown in Fig. 4c-e. When the post-oxidation process is carried out with environmental air (Fig. $4 \mathrm{f}-\mathrm{h}$ ) and without using $\mathrm{H}_{2}$, this hematite peak decreases to be almost extinguished as shown in Fig. $4 \mathrm{~g}$, in a condition in which the sample was nitrided for $2 \mathrm{~h}$. To explain the in-depth oxidized magnetite layer, it is suggested that hydrogenous species from the plasma, e.g. OH [11] are electrons carriers which due to their migration capability through grain boundaries, cracks and pores could reach deeper layers, releasing $\mathrm{H}$ to avoid formation of hematite via the intermediate reaction $\mathrm{Fe}: \mathrm{OH}$ [12]; we believe that the $\mathrm{OH}$ species stem from the humidity of environmental air. Moreover, we think that nitrogen also plays a catalytic role in the magnetite formation at least if the percentage of nitrogen $(\approx 80 \%)$ in the oxygen and nitrogen mixture is taken into account.

In general, the potentiodynamic tests displayed in Fig. 5 present a shift to higher potential $\left(E_{\text {corr }}\right)$ values and lower corrosion currents $\left(i_{\text {corr }}\right)$ when it compares the post-oxidized specimens with the untreated and only nitrided ones (see Table II). $\left(i_{\text {corr }}\right)$ was calculated by the Tafel slopes with a software incorporated to the PC. It should be noted that the better electrochemical performance obtained for the samples post-oxidized in only environmental air (Fig. 5d-e) being the best (Fig. 5e) due to the lowest $\left(i_{\text {corr }}\right)$ which is consistent with the low content of above mentioned hematite. Nevertheless for the sample treated for $3 \mathrm{~h}$ of nitriding and $1 \mathrm{~h}$ of post-oxidizing in dry air-like (sample c, Table II and Fig. 5, label c) a poor corrosion performance is observed.

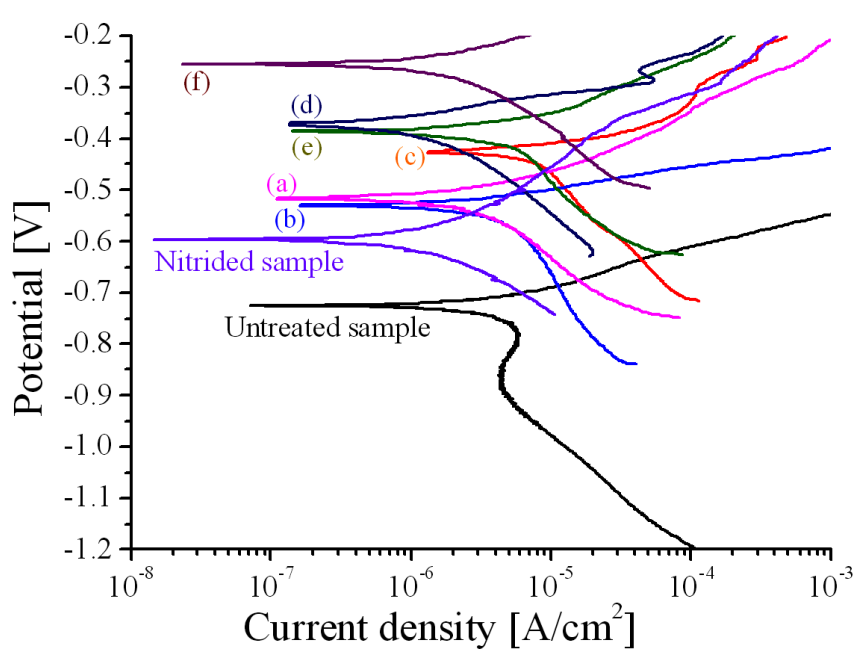

Fig. 5. Potentiodynamic tests of AISI 4140 untreated, nitrided sample, (a) $1 \mathrm{hN}+1 \mathrm{hPO}$ dal , (b) $2 \mathrm{hN}+1 \mathrm{hPO}$ dal, (c) $3 \mathrm{hN}+1 \mathrm{hPO}_{\text {dal }}$, (d) $1 \mathrm{hN}+1 \mathrm{hPO}_{\text {air }}$, (e) $2 \mathrm{hN}+$ $1 \mathrm{hPO}$ air, (f) $3 \mathrm{hN}+1 \mathrm{hPO}_{\text {air }}$.

The surface hardness of all nitrided and post-oxidized pieces in dry air-like is on the average $740 \mathrm{HV}$ while with atmospheric air $755 \mathrm{HV}$ (see Table II), in both cases the microhardness is close to the only nitrided one, which means that microhardness is not compromised due to the presence of oxidized layer. The Vickers microhardness of the post-oxidized samples was less than the nitrided sample but was higher compared to the untreated one. 
Potentiodynamic test and microhardness results.

TABLE II

\begin{tabular}{c|c|c|c|c|c}
\hline \hline Sample & & $E_{\text {corr }}$ & $i_{\text {corr }}$ & \multicolumn{2}{c}{ Microhardness } \\
\cline { 5 - 6 }$($ Fig. 5) & Conditions & {$[\mathrm{mV}]$} & {$\left[\mathrm{A} / \mathrm{cm}^{2}\right]$} & {$\left[\mathrm{HV}_{500 \mathrm{~g}}\right]$} & relative to untreated and nitrided samples \\
\hline untreated & - & -725 & $2.48 \times 10^{-6}$ & 269 & 1 \\
\hline nitrided & $3 \mathrm{~h}$ & -595 & $5.02 \times 10^{-7}$ & 818 & 3.04 \\
\hline a) & $1 \mathrm{hN}+1 \mathrm{hPO}_{\text {dal }}$ & -515 & $3.37 \times 10^{-7}$ & 663 & $2.46 / 0.81$ \\
\hline b) & $2 \mathrm{hN}+1 \mathrm{hPO}_{\text {dal }}$ & -530 & $1.69 \times 10^{-7}$ & 759 & $2.82 / 0.93$ \\
\hline c) & $3 \mathrm{hN}+1 \mathrm{hPO}_{\text {dal }}$ & -424 & $4.24 \times 10^{-6}$ & 798 & $2.96 / 0.98$ \\
\hline d) & $1 \mathrm{hN}+1 \mathrm{hPO}_{\text {air }}$ & -371 & $2.97 \times 10^{-7}$ & 763 & $2.84 / 0.93$ \\
\hline e) & $2 \mathrm{hN}+1 \mathrm{hPO}_{\text {air }}$ & -385 & $1.42 \times 10^{-7}$ & 734 & $2.73 / 0.90$ \\
\hline f) & $3 \mathrm{hN}+1 \mathrm{hPO}_{\text {air }}$ & -255 & $5.32 \times 10^{-7}$ & 768 & $2.85 / 0.94$
\end{tabular}

\section{Conclusions}

$\mathrm{RF}$ inductive plasma discharge nitriding is a useful tool to nitride and post-oxidize low alloy steels. The postoxidation in both air and dry air-like ambient shows good corrosion performance after $2 \mathrm{~h}$ of nitriding process and $1 \mathrm{~h}$ of post-oxidation. With the post-oxidation in air, it is possible to obtain low content of hematite phase without using $\mathrm{H}_{2}$ or other gases, particularly with $2 \mathrm{~h}$ of nitriding. The microhardness is close to the value of nitrided samples after the post-oxidation process. Post-oxidation in atmospheric air seems to be an attractive method in operation of the process and from an economical point of view.

\section{Acknowledgments}

This project has been partially funded by CONACyT, Mexico. The authors are grateful to Carlos Salinas for the technical support in SEM diagnostics, Isidoro Martínez in XRD, Julio César Zenteno in corrosion tests and Pavel López in AFM. The technical assistance by Pedro Ángeles Espinoza, María Teresa Torres M. and Isaías Contreras Villa is much appreciated.

\section{References}

[1] A. Esfahani, H.H. Sohi, J. Rassizadehghani, F. Mahboubi, $\quad 10.1016 /$ j.vacuum.2007.05.005 Vacuum $\mathbf{8 2}$, 346 (2008).

[2] Y. Li, L. Wang, D. Zhang, L. Shen, Appl. Surf. Sci. 256, 4149 (2010).
[3] F. Mahboubi, M. Fattah, Vacuum 79, 1 (2005).

[4] M. Zlatanović, N. Popović, Ž. Bogdanov, S. Zlatanović, Surf. Coat. Technol. 177, 277 (2004).

[5] A.C. Rovani, R.R. Fischer, F. Cemin, F.G. Echeverrigaray, R.L.O. Basso, C.L.G. Amorim, G.V. Soares, I.J.R. Baumvol, C.A. Figueroa, Scr. Mater. 62, 863 (2010).

[6] N. Karimzadeh, E.G. Moghaddam, M. Mirjani, K. Raeissi, Appl. Surf. Sci. 283, 584 (2013).

[7] M. Mirjani, J. Mazrooei, N. Karimzadeh, F. Ashrafizadeh, Surf. Coat. Technol. 206, 4389 (2012).

[8] J.M. Hong, Y.R. Cho, D.J. Kim, J.M. Baek, K.H. Lee, Surf. Coat. Technol. 131, 548 (2000).

[9] A. Alsaran, H. Altun, M. Karakan, A. Çelik, Surf. Coat. Technol. 176, 344 (2004).

[10] A. de la Piedad-Beneitez, A.E. Muñoz-Castro, R. Valencia-Alvarado, R. López-Callejas, A. MercadoCabrera, R. Peña-Eguiluz, B. Rodríguez-Méndez, S.R. Barocio, Acta Phys. Pol. A 123, 904 (2013).

[11] L. Magne, S. Pasquiers, K. Gadonna, P. Jeanney, N. Blin-Simiand, F. Jorand, C. Postel, J. Phys. D Appl. Phys. 42, 165203 (2009).

[12] C. Luvison, V. Sonda, A.C. Rovani, F. Cemin, F.G. Echeverrigaray, C. Aguzzoli, A.E. Crespi, C.L.G. Amorim, M.E.H. Maia da Costa, I.J.R. Baumvol, C.A. Figueroa, Vacuum $\mathbf{8 6}$, 1268 (2012) 